\title{
El lugar de los abuelos en el seno de las familias. Reflexiones sobre el Derecho argentino
}

Grandparent's place within the families. Considerations on Argentine Law

Autor: Florencia Vazzano

DOI: http://doi.org/10.25058/7794600X.1792 


\title{
EL LUGAR DE LOS ABUELOS EN EL SENO DE LAS FAMILIAS. REFLEXIONES SOBRE EL DERECHO ARGENTINO*
}

\author{
Grandparent's place within the families. Considerations \\ on Argentine Law
}

\author{
O lugar dos avós nas famílias. Reflexões sobre \\ o Direito argentino
}

\author{
Florencia Vazzano ${ }^{a}$ \\ florencia.vazzano@azul.der.unicen.edu.ar
}

Fecha de recepción: 13 de marzo de 2020

Fecha de revisión: 22 de marzo de 2020

Fecha de aceptación: 01 de abril de 2020

\section{RESUMEN}

DOI: http://doi.org/10.25058/1794600X.1792

Para citar este artículo:

Vazzano, F. (2020). El lugar de los abuelos en el seno de las familias. Reflexiones sobre el Derecho argentino. Revista Misión Jurídica, 13, (19), 158-168.

En la actualidad se observa el quiebre - o al menos del debilitamiento-, de los tres elementos sobre los cuales se diseñó la estructura familiar tradicional: el sexo, la edad y la consanguinidad. En relación al primero, la emancipación femenina, ocurrida a partir de la segunda mitad del siglo XX, condujo a la inserción de las mujeres en el espacio productivo-laboral, generando las condiciones para que las madres requieran de la colaboración de los abuelos en el cuidado de sus hijos menores de edad. A ello se suma el incremento reciente de divorcios y separaciones de las parejas que conformaban las familias nucleares, todo lo cual supone -ante la ruptura de esas uniones- un lugar preponderante de los abuelos en el cuidado y contención de los más pequeños de la familia. En relación al segundo componente, se produjo la democratización de las relaciones intrafamiliares, permitiendo que quienes históricamente permanecieron como sujetos subordinados, puedan gozar de su derecho a la autonomía y libertad personal, en condiciones

\footnotetext{
* El presente artículo de reflexión se realizó en el marco de la investigación que la autora realiza en el Proyecto de Investigación "Persona, Autonomía y Protección en la Teoría del Derecho", radicado en el Instituto de Estudios Jurídicos y Sociales (IEJUS), de la Facultad de Derecho, UNICEN. El mismo se realiza bajo la dirección la Prof. Dra. María Isolina Dabove y la codirección de la Prof. Mag. Guillermina Zabalza, con fecha de vigencia 1/1/2019 a 31/12/2021. .

a. Abogada. Magister en Derecho Privado por la Facultad de Derecho, UNR. Docente en la asignatura Teoría General del Derecho, y Filosofía del Derecho de la Facultad de Derecho, UNICEN. Investigadora integrante del Instituto de Estudios Jurídicos y Sociales (IEJUS), de la Facultad de Derecho, UNICEN.
} 
de igualdad y dignidad, dentro de ellos, los abuelos o bisabuelos personas mayores. En cuanto al tercer elemento, se reconoció a la socioafectividad como requisito determinante de las relaciones interpersonales, a la par del presupuesto biológico, dando lugar a planteamientos e interrogantes en torno del lugar de los abuelos afines en el marco de la familia ensamblada. En definitiva, los sucesos mencionados han operado como factores para una relectura jurídica de los roles de los abuelos en el seno de las familias.

\section{PALABRAS CLAVES}

Abuelos; familias; cuidado; nietos; autonomía; igualdad; diversidad, abuelidad.

\section{ABSTRACT}

Nowadays, the three elements on which traditional family structure has been designed like gender, age and consanguinity are broken -or at least weakened-. In accordance with the former, female emancipation which took place from the second half of the 20th century on, led to the inclusion of women in productive-working spaces, generating the conditions for the mothers to request help from the grandparents in the care of minor children. In addition to this, the recent increase in divorces and separations of couples who constituted nuclear families results in -before the breakdown of these unions- an important place of grandparents in the care and support of the youngest members of the family. With reference to the second element, there has been a democratization of intra-familiar relationships allowing for those who have been historically seen as subordinate subjects to enjoy their right to autonomy and personal freedom, in conditions of equality and dignity, including grandparents or great-grandparents, elderly people. With regards to the third element, socio-affectivity has been recognized as a determining requirement for interpersonal relations, on par with the biological budget, giving rise to approaches and questions regarding the place of kindred grandparents within the framework of assembled families. In essence, the abovementioned events have operated as factors for a re-reading of the legal roles of grandparents within families.

\section{KEY WORDS}

Grandparents, family, care, grandchildren, autonomy, equality, diversity, grandparenthood.

\section{RESUMO}

$\mathrm{Na}$ atualidade, observa-se a ruptura - ou pelo menos o enfraquecimento - dos três elementos sobre os quais foi desenhada a estrutura familiar tradicional: sexo, idade e consanguinidade. Em relação à primeira, a emancipação feminina, ocorrida a partir da segunda metade do século XX, propiciou a inserção da mulher no espaço produtivo-laboral, gerando condições para que as mães necessitassem da colaboração dos avós para cuidar de seus filhos menores. Soma-se a isso o recente aumento de divórcios e separações dos casais que compunham as famílias nucleares, que supõem - antes da ruptura dessas uniões - um lugar preponderante para os avós no cuidado e apoio aos menores da família. No que se refere ao segundo componente, ocorreu a democratização das relações intrafamiliares, permitindo àqueles que historicamente permaneceram como sujeitos subordinados, gozarem do direito à autonomia e à liberdade pessoal, em condições de igualdade e dignidade, dentro deles, seus avós ou bisavós idosos. No que se refere ao terceiro elemento, a socioafetividade foi reconhecida como requisito determinante das relações interpessoais, juntamente com o pressuposto biológico, suscitando propostas e questionamentos sobre o lugar dos avós aparentados no quadro da família reunida. Em última análise, os eventos supracitados operaram como fatores para uma releitura jurídica do papel dos avós no seio familiar.

\section{PALAVRAS-CHAVES}

Avós; famílias; cuidado; netos; autonomia; igualdade; diversidade, vovó.

\section{INTRODUCCIÓN}

El devenir de las transformaciones sociales suscitadas desde el siglo XX hasta la actualidad muestran diversos roles, lugares y espacios de las personas dentro de la organización de la familia, cuya historia como institución social no es más que el resultado de sucesivas construcciones sociales, culturales, económicas, políticas y jurídicas sobre diversos modelos familiares que han delineado los roles de sus integrantes y sus vinculaciones dentro de la misma (Jelin, 1996). Un recorrido por esa historia refleja el paso de una construcción basada en un único modelo, a una construcción más plural, sustentada en el reconocimiento de múltiples formas de organización familiar, siendo este el modelo que llega hasta nuestros días (Jelin, 
1996). En ese marco de pluralidad familiar, se atribuyen a los abuelos funciones preponderantes $\mathrm{y}$ significativas frente a entramados familiares que exhiben ausencias, imposibilidades $\mathrm{y} / \mathrm{o}$ incumplimientos por parte de los progenitores -principales responsables del cuidado de los niños, niñas y adolescentes.

Partiendo de estas ideas iniciales, el propósito de este trabajo es realizar un análisis del tema tomando tres elementos: el sexo, la edad, y la consanguinidad, en función de las ideas desarrolladas por Elizabeth Jelin (1996) en su trabajo "Familia: crisis y después". La autora señala que existen principios básicos de organización interna de la familia que han marcado diferenciaciones según edad, sexo $\mathrm{y}$ parentesco. Dichos criterios, han trazado roles, lugares y espacios diversos para las personas dentro de la familia y de la sociedad en su conjunto. En la actualidad, se observa el quiebre - o al menos del debilitamiento-, de los tres elementos señalados, todo lo cual se produjo a partir de la puesta en crisis del modelo familiar tradicional. Los cambios en los tres componentes han marcado nuevos roles y lugares de los abuelos en el seno de las familias, y de la comunidad en su conjunto.

\section{EL LUGAR DE LOS ABUELOS DENTRO DEL MODELO DE DIVERSIDAD FAMILIAR. S. XX Y XXI (TIEMPOS DE LA POSMODERNIDAD)}

La llegada de la postmodernidad produjo la ruptura de las bases sobre las cuales se edificó originariamente el Derecho de Familia. Las nuevas realidades y exigencias de justicia que se presentaron desde mitad del siglo XX pusieron en crisis el modelo de familia nuclear, determinando el fin de su predominio dentro de la sociedad (Mizrahi, 1998). Dicha visión acerca de la organización familiar constituyó la forma ideal y normal de planificar la institución familiar, sin embargo, comenzó a desmoronarse cuando profundos cambios sociales, económicos, científicos, políticos, culturales, jurídicos, generaron replanteos en torno a los siguientes tres elementos: el sexo, la edad y la consanguinidad.

En relación al primero, la emancipación femenina ocurrida a partir de la segunda mitad del S. XX debilitó el poder masculino, determinando el quiebre de la división sexual del trabajo de la sociedad industrial (Mizrahi, 1998). Esto se convirtió en el escenario propicio - junto con la crisis de la familia matrimonial-, para el nacimiento de nuevos roles por parte de los abuelos dentro del desenvolvimiento familiar. En relación al segundo elemento, se logró la democratización de las relaciones intrafamiliares, permitiendo que quienes históricamente permanecieron como sujetos subordinados, puedan gozar de su derecho a la autonomía y libertad personal, en condiciones de igualdad y dignidad (Herrera, 2011). En relación al tercer elemento, se reconoció a la socioafectividad como requisito determinante de las relaciones interpersonales, a la par del presupuesto biológico. Ello en un marco de coexistencia de nuevas formas de organización familiar que despertó nuevos interrogantes y desafíos para la ciencia jurídica.

\subsection{La inserción de la mujer en el espacio laboral}

El siglo XX ha marcado el surgimiento del Derecho Internacional de los Derechos Humanos, consolidado mediante el proceso de positivización de los derechos fundamentales de todas las personas, y de inserción en los ordenamientos internos de los Estados. Dentro de ese camino de reconocimiento de derechos, ciertos sujetos son destinatarios de una protección más específica, en atención al lugar que históricamente han ocupado dentro de la familia y de la sociedad en general. Las rupturas señaladas en torno a esos tres elementos (sexo, edad y consanguinidad) responden al proceso de reivindicación de las mujeres, de los niños, niñas y adolescentes y de las personas en la vejez, y en particular, a la consolidación de su autonomía y libertad personal, igualdad y dignidad (Jelin, 1996). Siguiendo a Marisa Herrera, el paradigma de los derechos humanos ha creado las condiciones para situarnos en otro lugar desde donde observar, además de proporcionar herramientas de cómo observar y qué observar (Herrera, 2011).

A partir de la segunda mitad del siglo XX, se produjo un fenómeno de inserción y participación de las mujeres en el mercado del trabajo. Esto debido a que el sexo femenino logró salir del espacio doméstico y emigró de manera masiva al ámbito laboral e intelectual. 
En el siglo XXI, las mujeres han logrado conquistar, e incluso protagonizar, el espacio público, y se encuentran trabajando, estudiando, ocupando cargos políticos. Actualmente, se tiende a disociar los roles de las mujeres con la función de reproducción, hoy muchas sueñan con el éxito profesional, la popularidad, el reconocimiento, la independencia, ser investigadoras, modelos, actrices, ejecutivas, líderes, etc. Esto debido a que se han asentado las bases para construir una nueva identidad femenina, que modifique su sentido de pertenencia tradicional (Murillo, 1996).

En muchos casos, la vida posmoderna caracterizada por el consumo masivo en sociedades altamente globalizadas y tecnologizadas, así como también, los tiempos de crisis económicas y de desempleo, han contribuido al cambio de roles de las mujeres, en tanto, se han insertado en el campo laboral para mantener el nivel de vida familiar (Sánchez Martínez, 2010).

El mundo jurídico fue acompañando los cambios sociales postindustriales, y ha concedido a las mujeres ese espacio de libertad y de autonomía personal que resulta indispensable para personalizarse, todo ello, a su vez, en un marco de igualdad con los hombres (Lloveras; Ciuro Caldani, 2010). Posicionadas desde un lugar más humano, más justo, más igualitario en relación al sexo masculino, las mujeres de hoy no sólo deciden autónomamente trabajar, estudiar, capacitarse, viajar, proyectar o emprender, sino también, procrear y criar a sus hijos en las diversas estrategias familiares que pueden pensarse y proyectarse en cada contexto histórico. A la inversa, los hombres fueron ingresando al ámbito doméstico o privado, ante las necesidades de reorganización familiar, y como compensación frente al desborde femenino en el terreno público (Lipovetsky, 1986, citado por Mizrahi, 1998). Este espacio dejó de ser exclusivo del sexo masculino; por ende, la posmodernidad muestra hombres que se ocupan de los quehaceres de la casa y del cuidado de los hijos.

Por otro lado, a partir del siglo $\mathrm{XX}$ se incrementó el número de divorcios y de separaciones de las parejas que conformaban las familiares nucleares ${ }^{1}$. Todo ello provocó el

1. A la par, se incrementó el número de uniones convivenciales debilitamiento de la familia matrimonial, y el surgimiento y auge de la familia monoparental. Siguiendo a Adriana Krasnow (2015), este tipo familiar es el que mayor incremento ha tenido en las últimas décadas a partir de la ruptura de los vínculos que unían a los progenitores. Ello puede darse por divorcio; separación de hecho; cese de la unión convivencial; así como también, porque las mujeres recurren a una técnica de inseminación artificial o fecundación heteróloga y son madres solas (solteras o cabeza de familia en otras latitudes); o simplemente, porque nunca han conformado una comunidad de vida ${ }^{2}$.

Este nuevo tipo de familia ha llevado al debilitamiento del ideal de convivencia y techo común entre padres e hijos comunes, -característico del modelo tradicional- (Jelin, 1996), considerando que se trata de una estructura familiar que muestra la concentración de la función de cuidado de los niños, niñas $\mathrm{y}$ adolescentes en uno de los progenitores El quiebre de la tradicional división sexual del trabajo, sumado al surgimiento y aumento de la familia monoparental, no sólo trajo cambios en los roles y el lugar de las mujeres y de los hombres, sino que también, produjo su impacto en las funciones de los abuelos.

Considerando que en la posmodernidad la mujer conquista un nuevo lugar tanto en las interacciones intrafamiliares como en las laborales, las tareas de cuidado se piensan desde una distribución de roles compartidos y alternados entre ambos progenitores, así como también a cargo de otros integrantes de la familia, como los abuelos y/o bisabuelos. Ante las diversas realidades laborales de ambos progenitores, éstos últimos toman un rol preponderante en el cuidado de sus nietos menores de edad. Siguiendo a Elizabeth Jelin (2016), se observa que un gran número de familias de la posmodernidad se desenvuelven en un marco de redes de ayuda mutua entre parientes, de gran importancia en la organización de la cotidianidad. Esto ocurre en todos los sectores sociales, pues aun cuando las clases medias y altas pueden recurrir a las guarderías o al servicio doméstico, es frecuente

que dio lugar a la familia nuclear extramatrimonial. Véase sobre el tema, Geldstein (1996).

2. Otras de las causas que dan lugar a la familia monoparental es la muerte de uno de los cónyuges o convivientes; la nulidad del matrimonio; la adopción; la guarda unipersonal (Krasnow, 2015). 
apelar al cuidado por parte de los ascendientes (Ortiz Barbero, 2010).

Las funciones desarrolladas por uno de los progenitores en las familias monoparentales ${ }^{3}$ necesita muchas veces complementarse con el rol de cuidado de otros ascendientes cuando los progenitores a cargo trabajan; e incluso, con el rol de alimentación, cuando aquellos asumen el pago de la obra social, gastos en educación, vestimenta, alimentos a favor de sus nietos o bisnietos menores de edad, ante la insuficiencia de ingresos del progenitor que convive con los hijos y frente al incumplimiento del otro.

La ruptura de la pareja implica una nueva reorganización familiar, y en ese contexto, puede suceder que los progenitores que dejan de convivir con los hijos se desentiendan de sus deberes-derechos derivados de la responsabilidad parental. Es allí cuando los abuelos se encuentran ante la situación de colaborar con un rol más activo con el progenitor que queda conviviendo con los hijos, a fin de procurar la satisfacción de las necesidades propias de la niñez y de la adolescencia (Segalen, 2013). En numerosos casos, los abuelos (padres del progenitor incumplidor o ausente) son demandados judicialmente al pago de una cuota alimentaria por parte del progenitor que está a cargo del cuidado de esos niños, niñas y adolescentes.

Asimismo, los abuelos cumplen la función de guardadores de sus nietos cuando se aplican medidas de protección especial en el marco de la ley $26.061^{4}$, o de la figura de la guarda otorgada a pariente de acuerdo a lo prescripto por el art. 657 del Código Civil y Comercial argentino. Al respecto, la Comisión Interamericana de Derechos Humanos (2013) ha dicho que, en los casos de separación temporal de los niños, niñas de su núcleo familiar, en la medida de lo posible, se busca conservar el cuidado a cargo de su familia extensa o ampliada, en cuanto ello resulta particularmente respetuoso del derecho a la familia y a la identidad del niño, niña o adolescente.

3. El Código Civil y Comercial prevé el cuidado personal de los hijos en forma conjunta indistinta como regla. Asimismo, regula el cuidado conjunto alternado. Excepcionalmente, permite el cuidado unipersonal.

4. Ley de protección integral de los derechos de los niños, niñas y adolescentes, sancionada en 2005.
En el modelo actual, ya no domina la imagen de la familia conformada por los cónyuges y sus hijos comunes, sino que también ha cobrado especial importancia la familia extensa o ampliada. En ese marco, se incluyen todos los lazos que los niños, niñas y adolescentes mantienen con otras personas, distintas de sus progenitores, vinculadas "a través de líneas de parentesco por consanguinidad o por afinidad, o con otros miembros de la familia ampliada" (art. 7o del decreto 415/2006).

Al respecto, Jelin da cuenta del entramado de interacciones que se entablan entre sus integrantes:

Un techo y un corazón son los elementos que asociamos con la idea de familia: la convivencia, el techo común, el amor, el afecto, el cuidado. La familia se extiende más allá de este techo común, con responsabilidades, afectos y tareas hacia vínculos que no implican convivencia, de ahí el techo abierto (Jelin, 1996: 23).

En la segunda parte de esta proposición se realza la presencia de la familia ampliada; la autora expone las responsabilidades y tareas que asumen los abuelos y otros parientes de los niños, niñas y adolescentes; y deja ver que se entretejen vínculos afectivos con otros integrantes de la familia, distintos de los progenitores, incluso con terceros.

La institución familiar "ha dejado de ser, esencialmente, un núcleo económico y de reproducción para ser un espacio de afecto y de amor" (Da Cunha Pereira, 2006: 23. Citado por Herrera, 2013). Hoy la ciencia del Derecho, busca visibilizar y revalorizar la trascendencia de los lazos significativos y afectivos de quienes están en la niñez y la adolescencia (art. 8o, Convención sobre los Derechos del Niño). En ese marco, se otorga importancia a las relaciones intergeneracionales entre nietos y abuelos. Se ha dicho que la figura de los abuelos ocupa un lugar importante para los nietos, tanto en el plano afectivo como en su socialización (Kemelmajer de Carlucci, 2006), no sólo como proveedores de cuidados y asistencia económica, sino también, para la reafirmación de su identidad y su pertenencia al grupo ${ }^{5}$.

5. Al respecto, cabe destacar que el orden jurídico español ha 
Alicia Husni y Fernanda Rivas (2007), dos psicólogas argentinas, han destacado que el funcionamiento del vínculo abuelos/nietos es sumamente complejo y ha sido poco estudiado, advirtiendo la relevancia que tienen las distintas interacciones intergeneracionales y afectivas que pueden llegar a condicionar el acontecer de toda una estructura familiar. Hoy se intenta desde la perspectiva jurídica lograr una "abuelidad saludable", donde todos los integrantes de la relación -incluyendo a los progenitores - se sientan "escuchados" y tengan un espacio propio en el Derecho Constitucional de Familias.

En ese marco, se denomina abuelidad al vínculo y rol que se entrama al interior de la organización familiar (Iacub, 2015). La llegada de la vida posmoderna muestra el paso de una abuelidad pensada y ejercida de manera secundaria, pasiva, a una abuelidad más activa y significativa para los más pequeños y jóvenes de las familias. Por lo tanto, hoy la familia ampliada tiene su espacio en el Derecho junto con la familia nuclear, en tanto, no sólo importan las relaciones paterno-filiales, sino también, todas las interacciones que la persona mantiene con el resto de sus parientes, e incluso, con terceros que constituyen referentes socioafectivos.

\subsection{La democratización de la relaciones familiares}

Por otro lado, la edad dejó de ser un criterio para diferenciar los derechos, facultades, roles, ámbitos de actuación, de quienes conforman las familias. Hoy los niños, niñas y adolescentes, así como las personas en la vejez han dejado de ser sujetos jurídicamente subordinados. Se pretende instaurar una cultura de derechos por oposición a una cultura de dominación (Grosman, 1996), donde las relaciones intrafamiliares ya no se construyen sobre la base de distinciones por edad, en el sentido de establecimiento de facultades o poderes de unos sobre otros, sino sobre la consagración y respeto de la autonomía,

reconocido la trascendencia de los vínculos entre abuelos y nietos mediante la sanción de la ley 42/2003, cuya Exposición de Motivos subraya el lugar fundamental que ocupan los abuelos en la "cohesión y transmisión de valores en la familia"; destacando que "disponen de una autoridad moraly de una distancia respecto de los problemas de la pareja que puede ayudar a los nietos a racionalizar situaciones de conflicto familiar, favoreciendo en este sentido su estabilidad y desarrollo" (Grosman-Herrera, 2011). la libertad y la igualdad en las relaciones interpersonales.

En este contexto, los abuelos y/o bisabuelos que transitan su vejez cuentan hoy con respuestas jurídicas especiales, que garantizan derechos que se reconocen como propios de esta etapa de la vida. Esta mirada particular que ofrece el mundo del Derecho, se asienta sobre la consideración de aquellas vulnerabilidades que atraviesan las personas por encontrarse en la última etapa de la vida (Luna, 2008). Esto, por cuanto la vejez supone transformaciones en el aspecto físico, psíquico y laboral de la persona que se traducen en un cambio en la autovaloración, así como en la relación con la sociedad y con su familia (DabovePrunotto, 2006; Dabove-Di Tulio Budassi, 2014).

Se ha logrado así la consagración de la autonomía, la participación y autorrealización de las personas durante la vejez, en atención a las situaciones de vulnerabilidad socio-cultural, económica, política, jurídica, que se presentan como rasgos distintivos de esta etapa vital. En el ámbito del sistema de protección interamericano, la preocupación por las problemáticas concretas que se observan durante la vejez ha generado espacios de debate y deliberación acerca de los derechos de las personas mayores, todo lo cual ha llevado a la aprobación del primer documento internacional de carácter vinculante para los Estados partes: la Convención Interamericana sobre Protección de los Derechos Humanos de las Personas Mayores, de junio de 20156. Dicho instrumento internacional resalta la importancia de las interacciones intergeneracionales, conforme se desprende del principio de solidaridad y fortalecimiento de la protección familiar y comunitaria, enunciado en el art. $3^{\circ}$ inc. J. Dicho principio se encuentra íntimamente vinculado con el derecho a la participación, plasmado en el art. $8^{\circ}$ inc. b de la misma convención, el cual establece que los Estados: "Promoverán la participación de la persona mayor en actividades intergeneracionales para fortalecer la solidaridad y el apoyo mutuo como elementos claves del desarrollo social". Asimismo, se vincula con su derecho a la autonomía previsto en el art. $7^{\circ}$, cuya consagración tiene por finalidad garantizar un ámbito de inmunidad y no sujeción para la persona (Dabove, 2018).

6. Aprobada en Washington por la Asamblea General de la OEA el 15 de junio de 2015. 
Argentina es uno de los países de Latinoamérica que prontamente ratificó e incorporó a su derecho interno a la mencionada convención ${ }^{7}$, cuyo texto refuerza la protección que emana de diversas reglas de sotf law (Plan de Viena de 1982 y de Madrid de 2002, Principios de Naciones Unidas a favor de las Personas de Edad ${ }^{8}$; así como también, se suma a la protección que surge del bloque de constitucionalidad, compuesto por el texto de la Constitución Nacional y demás instrumentos internacionales sobre derechos humanos con jerarquía constitucional (art. 75 inc. 22) ${ }^{9}$.

Desde ese marco jurídico que tutela de modo especial a las personas en la vejez, es posible afirmar que las funciones de cuidado que los abuelos y/o bisabuelos desarrollan en la familia se traducen en ejercicio y disfrute de aquellos derechos-principios mencionados: autonomía, participación y solidaridad en las interacciones intergeneracionales.

Desde la mirada científica y tecnológica, se observa un mejoramiento de la calidad de vida de la población, con el consiguiente crecimiento de la expectativa de vida. Este hecho ha permitido denominar al siglo XXI como el siglo del envejecimiento demográfico, considerándose que se trata de un fenómeno que no tiene precedentes en la historia de la humanidad (Tomasello, 2002. Citado por Nawojczyk, 2009).

Los estudios sobre la vejez ya no están ceñidos al examen del costo social y de las políticas públicas, sino que desde el siglo XX, se asiste a un proceso de visibilización de sus problemáticas propias de manera integral, lo cual ha llevado al reconocimiento de sus derechos humanos, e incluso, a hablar de una nueva rama jurídica denominada Derecho de la Ancianidad o Derecho de la Vejez (Dabove, 2018).

Muchos abuelos de este siglo se sienten activos y su estado de salud les permite realizar numerosas actividades (laborales, educativas,

7. Incorporada por Argentina en mayo de 2017 mediante la ley 27.360 .

8. Aprobados por Resolución de la Asamblea General de Naciones Unidas de 16 de diciembre de 1991.

9. Dentro de los cuales se encuentra la Convención Americana sobre Derechos Humanos, los Pactos internacionales de 1966 (DCYP; DESC) y sus respectivos Protocolos, la Declaración Universal de los Derechos Humanos, entre otros documentos de protección general. recreativas o de esparcimiento). De allí que también desarrollan importantes roles dentro de las familias en beneficio no sólo de sus nietos, sino también de otros parientes o terceros. Las imágenes tradicionales de los abuelos retirados, hamacándose en los sillones o cocinando masitas, va dando lugar a otras imágenes con mayores más activos, en mejor estado físico, trabajando, con expectativas de vida más amplias y con muchos intereses personales (Segalen, 2013; Iacub, 2015). Actualmente, se tiende a una construcción social y cultural de la vejez alejada a la idea de vida debilitada, pasiva y retirada de épocas anteriores

\subsection{El reconocimiento de la socioafectividad}

Por último, la consanguinidad perdió su lugar predominante dentro del mundo jurídico. Hoy, las relaciones familiares se construyen a partir de vínculos sanguíneos y/ o afectivos (Famá-Herrera, 2008). La coexistencia de múltiples familias ha permitido visibilizar diversas interacciones entre las personas que no necesariamente están unidas por la sangre. En especial, se destaca el incremento de la familia ensamblada como otra de las formas de organización familiar ${ }^{10}$. La misma trajo al mundo jurídico nuevos conceptos construidos en respuesta a esa realidad social: el de "madre afín", "padre afín", "hijo afín", "abuelo afín", "nieto afín", "hermano afín". En definitiva, todos ellos reflejan la multiplicidad de nexos novedosos que se entablan en el seno de esta organización familiar y que han despertado nuevos problemas para el mundo jurídico.

En ese marco, la ciencia del Derecho se ha interesado de manera especial por todas aquellas interacciones que los niños, niñas y adolescentes mantienen con terceros que constituyen sus referentes confiables, y que contribuyen a la conformación de su identidad dinámica y a su formación como persona (Famá-Herrera, 2008). Se ha introducido así el concepto de socioafectividad como presupuesto determinante de relaciones interpersonales fundadas sobre la voluntad y el deseo de conservar lazos afectivos nacidos en los hechos (Herrera, 2014).

10. Siguiendo a Cecilia Grosman (2015) la familia ensamblada es aquella estructura familiar originada luego de la separación divorcio, o viudez, cuando uno o ambos integrantes de la pareja tienen hijos de una unión anterior, con o sin hijos comunes. 
La socioafectividad muestra la conjunción de dos elementos que lo integran y que hacen que lo fáctico sea lo esencial: lo social y lo afectivo; refleja cómo lo afectivo adopta un lugar de peso en lo social y cómo lo social se ve interpelado por ciertos y determinados afectos. A la vez, ambas ideas interactúan entre sí (Herrera, 2014). Estas vinculaciones trascienden las construcciones normativas, en cuanto, generan uniones entre un "yo" y "tú" que perduran y tienen sentido más allá de los vínculos creados por el mundo jurídico (Ciuro Caldani, 2009). De allí que resulta necesario distinguir el parentesco de sangre o legal, de aquel que se establece por la fuerza de los hechos (o los afectos) y que cuenta con una aceptación social que lo legitima (JuzgFam, $4^{\mathrm{a}}$ Nominación, Córdoba, 28/6/2010, “A. S. G. v. M. V. S. y otro s/medidas urgentes", Derecho de Familia, 2011-I-137).

En este contexto, los abuelos afines, es decir, los progenitores de quienes han formado una nueva unión conyugal o convivencial dando lugar a una familia ensamblada, pueden constituirse en referentes socioafectivos de los niños, niñas y adolescentes, en tanto, esta organización familiar se presenta como el marco propicio para que entre éstos y aquellos se entablen vinculaciones cercanas, cotidianas, y significativas para ambos.

$\mathrm{Si}$ los niños, niñas y adolescentes tienen su residencia en el domicilio de la familia ensamblada, o aunque sólo pasen algunas horas de su tiempo allí, aquel se convierte en el ámbito en el que los abuelos afines pueden desempeñar roles de contención, de transmisión de valores, de amor, afecto, e incluso, de cuidado hacia sus nietos afines, especialmente, cuando todos ellos juegan, comparten e interactúan con los hijos comunes de la pareja, hermanos unilaterales de aquellos niños, niñas y adolescentes ${ }^{11}$ y nietos biológicos de esos abuelos afines.

Actualmente, el complejo jurídico reconoce un derecho a la afectividad y al disfrute mutuo de las relaciones interpersonales, los cuales tienen su origen en el derecho humano a vivir en familia. Correlativamente, se establece la obligación del Estado de asegurar el ejercicio de estas perrogativas, evitando toda injerencia ilícita, ya

11. Hoy el Código Civil y Comercial en su art. 534 establece que hermanos unilaterales son quienes "proceden de un mismo ascendiente en primer grado, difiriendo en el otro". sea de terceros o de integrantes del mismo grupo familiar (Alcala, 2013).

La presencia activa de abuelos afines no implica una sustitución del lugar que corresponde a los abuelos biológicos, tampoco una superposición de roles, pues, en definitiva, lo que se pretende es anexar vínculos para quienes se encuentran en las etapas iniciales de la vida, cuando se trata de personas que contribuyen a su socialización y personalización. Actualmente, estos lazos de afecto se enmarcan dentro del concepto de familia ampliada del art. $7^{\circ}$ del decreto $415 / 06$, en tanto, establece que ésta comprende "(...) a las personas vinculadas a los niños, niñas y adolescentes, a través de líneas de parentesco por afinidad, o con otros miembros de la familia ampliada". E incluso "a otros miembros de la comunidad que representen para la niña, niño o adolescente, vínculos significativos y afectivos en su historia personal como así también en su desarrollo, asistencia y protección".

Suele reconocerse que el afecto, cariño, amor, contención, protección, son elementos inescindibles de los lazos biológicos; en otras palabras, que la sangre aparece como el vehículo que une a las generaciones y que crea entre los parientes lazos afectivos, de amor y protección (Jelin, 1996). Sin embargo, esos nexos pueden florecer por fuera o a la par de los vínculos consanguíneos, incluso, éstos no necesariamente son los que garantizan el respeto por el interés superior de los niños, niñas y adolescentes.

\section{CONCLUSIONES}

Las funciones de cuidado que los abuelos desarrollan dentro de la familia requieren de su relectura jurídica a partir del impacto de diversos sucesos históricos que han delineado un modelo de diversidad familiar, exhibiendo la crisis de los tres elementos sobre los cuales se diseñó la familia tradicional: el sexo, la edad y la consanguinidad.

El fenómeno de inserción y participación de las mujeres en el mercado del trabajo, así como la aparición de la familia monoparental, como estructura familiar que concentra los roles de cuidado en uno de los progenitores, se presentan como factores que han llevado a los abuelos a ocupar un lugar de enorme importancia para la organización y desenvolvimiento de la dinámica familiar. 
Asimismo, es frecuente que los abuelos asuman la función de guardadores de sus nietos cuando se aplican medidas de protección especial en el marco de la Ley 26.061, o por la guarda receptada en el art. 657 del Código Civil y Comercial, figuras que, en definitiva, reflejan la necesidad de que los niños, niñas y adolescentes permanezcan bajo el cuidado de integrantes de su familia ampliada. En otras palabras, el orden normativo revaloriza el lugar de la familia ampliada o extensa a partir de la consagración de los derechos de los niños, niñas y adolescentes, y del reconocimiento de la importancia del lugar de los abuelos en la estructura familiar.

En todos los casos, se trata de tareas de los abuelos dentro de entramados familiares diversos -donde uno o ambos progenitores pasan largas horas trabajando, o donde se observan sus incumplimientos o imposibilidades-. Frente a ello, debe destacarse la relevancia que su realización tiene para la satisfacción de derechos de los más pequeños y jóvenes de la familia.

Tratándose de abuelos y/o bisabuelos que transitan su vejez la importancia de sus roles encuentra su especial reconocimiento en todas aquellas respuestas jurídicas mediante las cuales se garantizan sus derechos humanos. Las funciones de cuidado dentro de la familia se enmarcan dentro del ejercicio y goce de su derecho a la autonomía, a la participación y autorrealización de las personas en la vejez, que hoy están consagrados en la Convención Interamericana sobre Protección de los Derechos Humanos de las Personas Mayores. Esta mirada especial por parte del mundo del Derecho se asienta sobre un dato sociológico que despierta enormes interrogantes y desafíos: el fenómeno del envejecimiento poblacional. Como tal, crea las condiciones para que en el seno de las familias se entablen interacciones entre generaciones más duraderas y significativas para todos los integrantes de la organización familiar.

La coexistencia de múltiples familias ha permitido visibilizar vínculos entre personas que no están unidas por la sangre, sino por la socioafectividad. Es allí donde debe destacarse el aumento de la familia ensamblada, en cuyo marco, la figura de los abuelos afines, puede resultar especialmente relevante para los niños, niñas y adolescentes que integran esa estructura familiar. En definitiva, se trata de pensar y repensar todos aquellos vínculos interpersonales que conducen a la formación y construcción de la identidad de las personas, generando posibilidades para proyectar el plan de vida en situación de libertad, igualdad y dignidad.

\section{BIBLIOGRAFÍA}

- ALCALA (2013). "Derecho a la afectividad", Derecho de Familia, no 59, p. 211.

- Ciuro Caldani, M.A. (2009). Los pronombres personales en el Derecho de Familia (nuevos aportes a la Filosofía del Derecho de Familia). En Kemelmajer de Carlucci (direct.). La familia en el nuevo Derecho, T. I. Buenos Aires: Rubinzal - Culzoni.

- ----. (2010). ¿Convertirse en persona? Revista de Familia y de las Personas $\mathrm{N}^{\circ} 1$. Buenos Aires: La Ley

- Dabove, P. L. (2006). Derecho de la Ancianidad. Rosario: Juris.

- -----. (2018). Derecho de la Vejez. Buenos Aires: Astrea.

- Da Cunha, Pereira (2006). Da uniao estável.
En Días, Da Cunha Pereira (direct.). Direito de Familia e o Novo Código Civil. Belo Horizonte: Del Rey- IBDFAM.

- Herrera, M y Famá, M. V. (2008). La obligación alimentaria de los abuelos de hoy. El Dial, (2659), suplemento especial.

- Geldstein, R. (1996). Familias con liderazgo femenino en sectores populares de Buenos Aires. En Wainerman (direct.). Vivir en Familia. Buenos Aires: Losada.

- Grosman, C., Herrera, M. (2011). Una intersección compleja: Ancianidad, abuelidad y Derecho de Familia. Oñati Socio-Legal Series, 1 (8). Recuperado en marzo 05 de 2020 de http://opo.iisj.net/ index.php/osls/article/view/97 
- Grosman C. (2015). La familia ensamblada: aspectos psico-sociales y jurídicos. En: Krasnow (direct.). Tratado de Derecho de Familia, T. I. Buenos Aires: La Ley.

- ----. (1996). Los derechos del niño en la familia. Ley, creencias y realidades. En Wainerman (direct.). Vivir en Familia. Buenos Aires: Losada.

- Herrera, M. (2011). La democratización de las relaciones de familia. Desafíos de la relación padres e hijos desde el principio de capacidad progresiva de niños, niñas y adolescente. Revista del Magíster y Doctorado en Derecho, (4): 17 - 56.

- -----. (2014). La noción de socioafectividad como elemento "rupturista" del Derecho de Familia contemporáneo. Derecho de Familia, (66): 65 - 113.

- -----. (2013). "Diversas formas de organización familiar y derechos humanos. Algunos apuntes sobre el Derecho de Familia contemporáneo", En: Reflexiones pragmáticas sobre Derecho de Familia (p.p. 137 - 173). San Salvador: Consejo Nacional de la Judicatura, Escuela de Capacitación Judicial (CNJ-ECJ). Recuperado el 01 de marzo de 2020 de http://www.cnj.gob.sv/ images/documentos/pdf/publicaciones/ ReflexionesPragmaticasSobreDerechoDeFa milia.pdf.

- Husni, A., Rivas, M. (2007). Familias en litigio. Perspectiva psicosocial. Buenos Aires: Lexis Nexis.

- Iacub, R. (2015). Familia y Vejez a propósito de la abuelidad. En: Krasnow (direct.). Tratado de Derecho de Familia, T.I. Buenos Aires: La Ley.

- Jelin, E. (1996). Familia: crisis y después. En Wainerman (direct.). Vivir en familia. Buenos Aires: Losada.

- -----. (2016). Pan y Afectos. Las transformaciones de las familias. Buenos Aires: Fondo de Cultura Económica.

- Kemelmajer de Carlucci, A. (2006). Las personas ancianas en la jurisprudencia argentina. ¿Hacia un derecho de la ancianidad? En Kemelmajer de CarlucciPérez Gallardo (directs.). Nuevos perfiles del Derecho de Familia. Santa Fe: Rubinzal Culzoni.

- Krasnow, A. (2015). La familia y sus formas. En Krasnow (direct.). Tratado de Derecho de Familia, T. I. Buenos Aires: La Ley.

- Lipovetsky, G. (1986). La era del vacío. Barcelona: Anagrama.

- Lloveras, N. (2010). "La mujer en los siglos XX y XXI". San Miguel: Consejo Nacional de la Judicatura. Recuperado en marzo 11 de 2020 de http://www.cnj.gob. sv/web/images/documentos/epaper/ ReflexionesPragmaticas/files/assets/ downloads/page0205.pdf.

- Luna, F. (2008). "Vulnerabilidad: la metáfora de las capas". Jurisprudencia Argentina, IV (1): 60 - 67.

- Mizrahi, M. (1998). Familia, matrimonio y divorcio. Buenos Aires: Astrea.

- Murillo, S. (1996). El mito de la vida privada. Madrid: Siglo XXI.

- Nawojczyk, E (2009). Derecho de la Ancianidad. Reflexiones sobre la construcción de esta rama jurídica a partir de la dikelógica trialista. Revista del Centro de Investigaciones de Filosofía Jurídica y Filosofía Social, (32): 75-80.

- Ortiz Barrero, M. J. (2010). Las abuelas como cuidadoras: una visión ecológica de su rol. Revista de Investigaciones, 9 (1): 225-240.

- Sánchez Martínez, M. (2010). Igualdad sexual y diversidad familiar: ¿La familia en crisis? Colección Cuadernos Cátedra de Democracia y Derechos Humanos, № 3 . España: Universidad de Alcalá.

- Segalen, M. (2013). Sociología de la Familia. Mar del Plata: Eudem.

- Tomasello, A. (2002). Derechos de la Ancianidad. Doctrina Judicial (3): 928-941. 